\title{
Study on Design Culture of Proto-porcelain Pot with Two Lugs of The Western Han Dynasty
}

\author{
Liu Mingyu* \\ Jingdezhen Ceramic Institute, Jingdezhen, Jiangxi,China \\ 115416121@qq.com
}

\begin{abstract}
Keywords: Pot with Two Lugs, Proto-porcelain, Water Ripple, Phoenix Bird Decorative Pattern, String Pattern, Animal Head Applique Holding Rings.
\end{abstract}

\begin{abstract}
The proto-porcelain pot with two lugs of the Western Han Dynasty was excavated in 1963 at Che jiabao of north suburb of Xi' An City, and which is collected in Shanxi History Museum. The pot with two lugs is proto-porcelain, and which has the transitional characteristics from pottery to porcelain. There are some patterns in the pot, such as water ripple, phoenix bird decorative pattern, and string pattern and so on; these patterns reflect the specific cultural features of the times.The two lugs of the pot with the form of animal head applique holding rings, which reflect the auspicious culture.
\end{abstract}

\section{西汉原始瓷双耳壶的设计文化探析}

\author{
刘明玉* \\ 景德镇陶瓷大学, 景德镇, 江西, 中国 \\ 115416121@qq.com
}

关键词：双耳壶；原始瓷；水波纹；凤鸟纹；弦纹；铺首衔环

中文摘要: 西汉原始瓷双耳壶于 1963 年出土于陕西省西安市北郊车家堡, 现藏于陕西历史博 物馆。该壶是原始瓷，具有由陶向瓷的过渡特征；装饰纹样有水波纹、鸟纹和弦纹等，这些 纹样都反映出特定时代的文化面貌; 该壶的双耳是铺首衔环耳, 反映出汉代时期趋吉避害的 文化特色。

\section{1. 引言}

西汉原始瓷双耳壸高 48 厘米、口径 16 厘米、足径 19.7 厘米, 方唇, 侈口, 高颈, 斜肩, 肩部两侧分别附着铺首衔环耳, 鼓腹, 圈足。腹部以上施釉, 釉色青中略泛黄, 釉层较厚。 腹部以下未施釉, 露红胎, 胎质坚硬。该壶器身有多组弦纹, 肩部两组弦纹之间刻划变体凤 鸟纹, 颈部及腹部各装饰一周水波纹。器型浑厚大方, 装饰纹样简洁、凝练, 釉色古朴, 反 映出西汉时期原始瓷设计及制作的水平 (图 1)。 


\section{2. 双耳壶的工艺特点}

中国是发明瓷器最早的国家, 原始 瓷是一种由陶向瓷过渡的青釉制品, 出 现于商代，东汉时完成了向瓷的过渡。 原始瓷是在制陶技术的基础上发展而 来的, 在由陶到瓷的嬗变过程中, 制坏 原料的耐火性成为与窑炉温度相辅相 成的因素。制陶的黏土中, 氧化硅和氧 化铝为主要成分, 黏土被火烧灼时, 氧 化硅在助熔物质的作用下, 熔融成能黏 合其他物质的玻璃相, 于是使黏土变得 坚硬而有强度。含有较多助熔物质的普 通黏土，耐火度不高，由其制成的陶胎 在超过 $1000^{\circ} \mathrm{C}$ 的窑温中, 就会出现软 塌变形的现象, 只有用助熔物质含量较 少的黏土制成的原始瓷胎, 才能在高温 焙烧时不变形, 而高温焙烧可使制品获 得更大的坚固度, 所以原始瓷比陶器更 耐高温, 更加坚固。

汉代原始瓷制坏技术成熟, 烧成温 度高, 胎质坚硬, 器形规整, 仅在仰面 上施釉, 以弦纹、水波纹、变形鸟纹和 铺首等为主要装饰。西汉双耳売就是这 一时期原始瓷的典型代表, 它的胎土中 含铁量较高, 在 $1.5 \%-3 \%$ 之间, 用

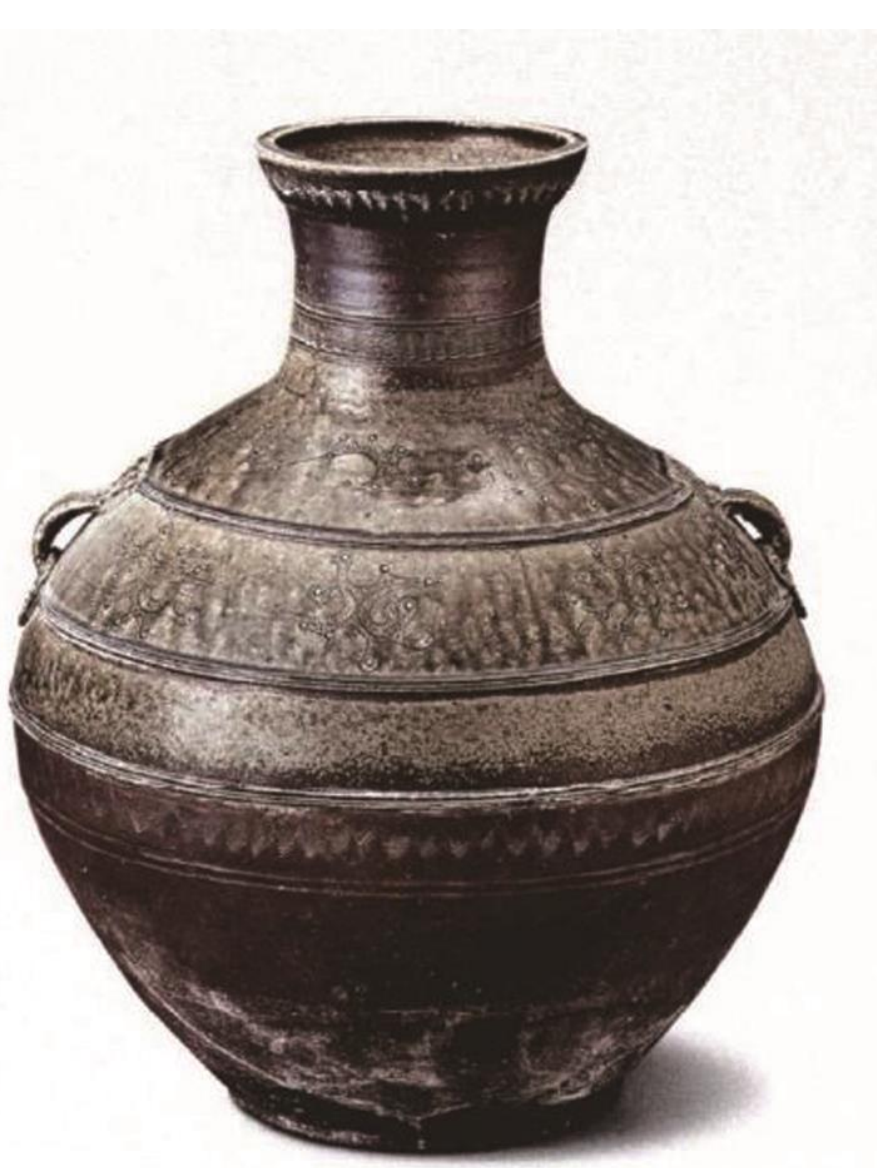

图 1 西汉原始瓷双耳壸 $1200^{\circ} \mathrm{C}$ 左右的高温, 在氧化焰中烧成, 所以胎体呈现砖红色; 使用的釉料是以铁为着色剂的 石灰釉, 氧化钙的含量高, 所以釉的高温粘度降低, 流动性较大, 在烧制时, 因为釉的流动 大, 常容易形成粘底缺陷, 该壸腹部以上施釉, 腹部以下不施釉, 避免了流釉产生的粘底缺 陷。该器物成型用快轮拉坏成器身, 再粘接器底而成, 器型规整, 器壁还留有轮旋的痕迹, 成型后还需要进行修坏、补水等工序，所以表面十分平整光滑。

\section{3. 双耳壶的装饰纹样}

\section{1 水波纹}

西汉原始瓷双耳壶的颈部及腹部各装饰一周水波纹。颈部水波纹是由横向展开的起伏曲 线组成, 起伏幅度小, 构成条带状, 规整严谨 (图 2)。腹部水波纹由起伏幅度较大的曲线组 成, 具有螺旋上升的趋势, 自由洒脱, 这种螺旋式的形态就像水波一样纵横穿插, 层层叠叠 犹如浪花前进, 蕴含着一种强烈的运动感与节奏感, 并向外膨胀, 形成具有张力的视觉表现。

(图 3)。

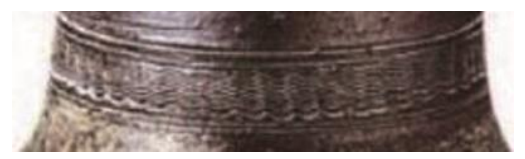

图 2 颈部水波纹

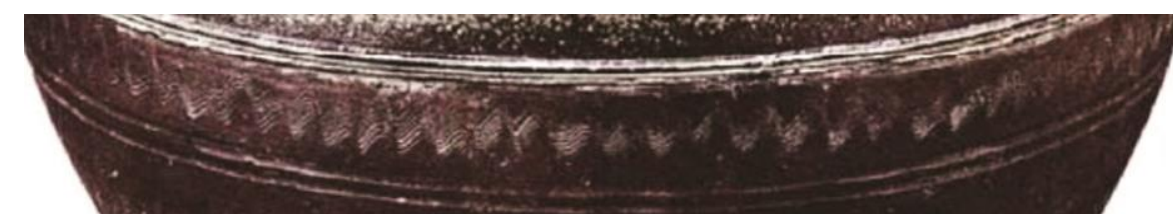

图 3 腹部水波纹 
自古以来，人的生活都离不开水，从生活用水、灌溉用水、到漕运，水都是人类生存环 境中最重要的组成部分。远古先民傍水而居, 他们观察水, 并用各种各样的方式去描绘水, 在新石器时代, 水就被人类以水波纹的形式刻画在陶器上, 水波纹是远古先民对自然之水的 抽象概括，体现了人们对自然的崇拜之情。从 “大禹治水”、“精卫填海” 等神话传说来看, 远古先民认识到水的神秘莫测的巨大威力与灵性, 用曲线这种基本元素, 创造出旋转上升的 水波纹, 用这种抽象艺术, 来表达对水的恐惧感和崇拜感。汉代原始瓷上, 水波纹装饰也成 为流行, 西汉原始瓷双耳売的水波纹根据器形位置的不同作出变化, 体现了器形与装饰的统 一，具有多样统一、对比调和、平衡对称等装饰特点。

水波纹的寓意与中国传统文化息息相关。老子的《道德经》记载: “上善若水，水善利万 物而不争”, 这句话的意思是，水滋养万物而不与万物发生矛盾、冲突，故天下最大的善性就 像水一样，因此，水被纳入到道德品行的最高境界。孔子也曾说过：“知者乐水”, 意思是聪 明人通达事理，反应敏捷而又思想活跃，性情好动就像水不停地流一样，这里把水同有智慧 的人相比拟，赋予了水更多的灵性气质。水波纹作为水的直观表现形态，也被世人赋予了厚 德载物、海纳百川的寓意, 教导人们具有包容的心态、智慧变通的修养。同时也体现出人与 水、人与自然和谐相处的自然追求。

\section{2 凤鸟纹}

西汉原始瓷双耳売肩部两组弦纹之间刻划变体凤鸟纹，呈展翅飞翔姿态，线条流畅，造 型简洁灵动。该纹样在器物肩部上下两层分布，呈二方连续展开 (图 4)。

凤鸟纹的出现缘于古代先民对 凤鸟图腾的崇拜。鸟鸣叫而日初升, 鸟与太阳同作息，这样的现象使得古 代先民对鸟产生敬畏; 鸟类遇危险能 展翅飞翔，避祸化吉，据此，人们赋 予了鸟类很多美好的想象，从崇拜敬

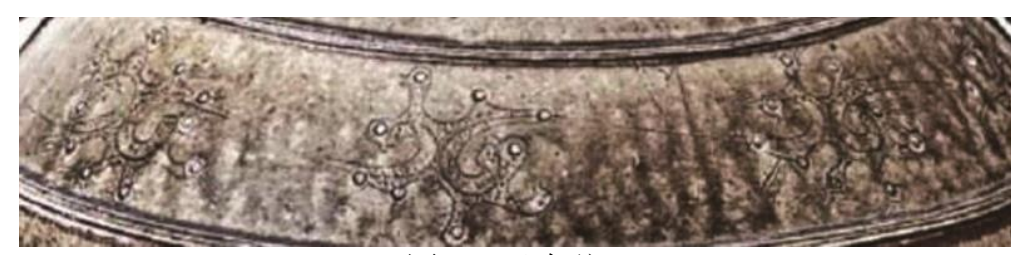

图 4 凤鸟纹 畏神格化的鸟图腾, 转化为吉祥寓意 的徽号, 进而被运用在器物的装饰之中。《春秋演礼图》记述 “凤为火精, 在天为朱雀”, 可 见凤鸟即为朱雀, 汉代崇尚 “四神”, 而朱雀是四神之一, 所以与朱雀形象有着千丝万缕联系 的风鸟纹在汉代得到流行。艺术内在的精神意蕴的演变离不开特定的历史环境下人的精神作 用, 而不同的艺术作品的精神意蕴, 同样可以反映这个时代的人的精神世界, 汉代黄老思想 盛行, 得道升仙成为世人的追求, 鸟有羽能飞, 飞是升天的重要手段, 所以人们期望能够像 鸟一样飞上仙境，因而风鸟纹装饰在器物上，也寓意着升仙的追求。

\section{3 弦纹}

西汉原始瓷双耳壶的颈部、肩部及腹部分别刻划有多组弦纹，其中颈部和下腹部的弦纹 较细, 肩部及上腹部的弦纹较粗, 相邻两组弦纹之间的距离有宽有窄, 形成了非常协调的对 比关系。

弦纹是在器物上刻划出的单一的或若干道平行的线条, 水平展开并环绕器物的颈、肩、 腹等部位, 它是器物上最简单的传统装饰纹样, 弦纹的出现与原始制陶中轮制方法的产生有 关，旋刻出来的弦纹又称旋纹。由于使用工具及处理方法的不同，弦纹有凹凸、粗细、尖方、 圆弧等不同形状，也有单线弦纹与复线弦纹之分，除此，还有用彩绘、堆贴等方法形成的弦 纹。

弦纹常作为界栏出现，与其它纹饰配合使用。西汉原始瓷双耳壶的颈部两组弦纹之间与 腹部弦纹两组弦纹之间都装饰有水波纹, 肩部弦纹之间装饰有凤鸟纹, 这里的弦纹就像画框 一样, 界定了水波纹和风鸟纹的位置, 使所有的装饰纹样都各据其位, 散而不乱。 


\section{4. 双耳壶的铺首衔环耳}

西汉原始瓷双耳壶的两个耳巧妙的设计成铺首衔环的式样。每个耳都是由两条并列的泥 条做成, 泥条上面有划出的平行的线纹, 弧形泥条耳上方是 “铺首” 形象, 下方穿挂着 “环” 的形象, “铺首” 和 “环” 是堆贴而成 (图 5)。

铺首衔环是中国古代门上的集装饰和实用于一体的 构件, 由门环和衔门环的底座构成, 铺首就是底座, 多为 兽面, 其鼻下或口部通常穿以圆环，即所谓 “铺首衔环”。 古代宅第大门多为双扇, 因而铺首常成对附着于左右门 上，其作用既可牵环便于开闭门户，又便于来访者以环扣 门。传说辅首是龙的第九个儿子, 性好静, 警觉性极高, 善于严把门户。铺首的形象源自于先秦的啹䬸纹, 饕䬸是 一种凶恶的神兽, 鼔䬸纹是一种兽面纹, 常有角纹、目纹、 鼻纹、口纹组成, 在先秦的铜器上便多出现餐䬸纹衔环的 装饰形象, 其后铺首在㛑䬸纹的基础上演变出多种造型, 既有非常简单的形状, 也有异常繁复逼真的凶猛奇兽的头 部形状, 铺首置于大门上, 用以驱邪, 保佑宅第平安。

铺首衔环最早出现在商代, 汉代的陶瓷器和青铜器以 及画像石、墓门以及棺楟上均有出现。汉代兽面铺首不但 承袭了商周兽面纹因素, 综合了许多兽类的特征, 也融入 了古代传说中虫尤等形象特征, 在此基础上进行夸张变

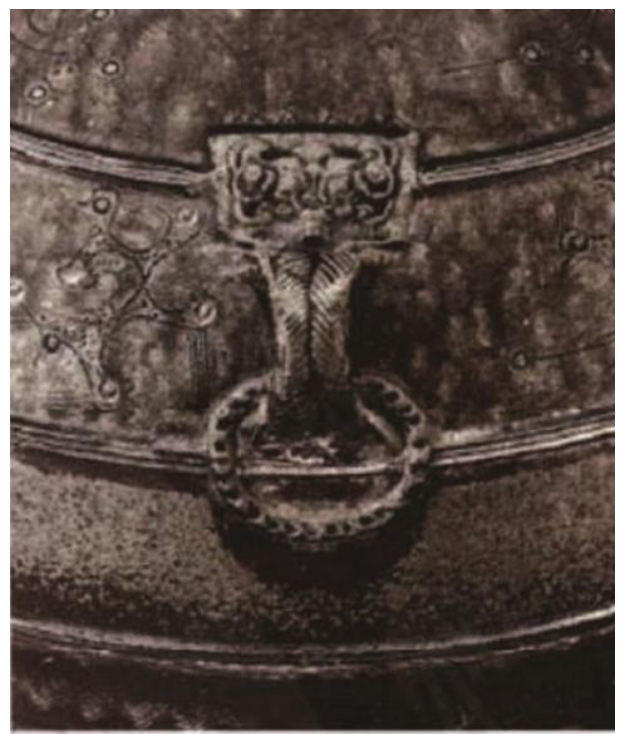

图 5 铺首衔环耳 形, 面目凶猛恐怖, 具有一种神秘的威力。西汉原始瓷双耳売的铺首衔环装饰, 表现了辟邪 求福的吉祥寓意。

\section{5. 结束语}

西汉原始瓷双耳壶用快轮拉坏的方法成型，烧成温度高，胎质坚硬，器形规整，在仰面 上施釉, 用刻划的装饰工艺装饰弦纹、水波纹、变形凤鸟纹, 用堆贴的装饰工艺装饰铺首衔 环双耳, 手法娴熟, 反映了西汉时期原始瓷的生产工艺。西汉原始瓷双耳壶的装饰纹样有弦 纹、水波纹、变形风鸟纹, 都承载了特定的时代文化, 弦纹象征着圆满、生生不息, 水波纹 象征着做人的德行和与自然和谐相处的追求, 凤鸟纹寓意着吉祥如意、得道成仙。西汉原始 瓷双耳売的铺首衔环耳, 既是实用性的构件, 便于穿上绳子提拿器物, 也是具有辟邪求福和 吉祥寓意的装饰。综上所述, 西汉原始瓷双耳売既是实用的生活器血, 也是蕴含着深厚文化 底蕴的设计艺术作品, 通过它, 可以窥探出西汉时期中国原始瓷的设计面貌。

\section{致谢}

本文为 2016 年度江西省文化艺术科学规划一般项目《中国瓷壶设计史》的阶段性成果之

\section{References}

[1] ZHANG Bo,The Complete Works of PorcelainUnearthed in China-15ShanXi, BeiJing:Science Press. pp4.2008.

[2] ZHOU Feng,ZHUANG Canhui,and MENG Xin.The Analysis of Iconology about the "Water Ripple" on the Ancient Potteries Unearthed in Our Country,Int. J. Creation and Design, vol.34 pp34-38,2014. 
[3]MIAO Xia,Simple Analysis on Chinese Ancient Jointed Ring, Int.J.Yindu Journal, vol.3 pp29-39,2006. 